OPEN ACCESS

Edited by:

Nathalie Just,

INRA Centre Val de Loire, France

Reviewed by:

Xun Yang,

Sichuan University, China

Benedikt Sundermann,

Evangelical Hospital

Oldenburg, Germany

Isabel Ellerbrock,

Karolinska Institutet (KI), Sweden

*Correspondence:

In-Seon Lee

inseon.lee@khu.ac.kr

Specialty section:

This article was submitted to

Brain Imaging Methods,

a section of the journal

Frontiers in Neuroscience

Received: 24 March 2021

Accepted: 02 June 2021

Published: 05 July 2021

Citation:

Kim D, Chae Y, Park H-J and Lee I-S (2021) Effects of Chronic Pain Treatment on Altered Functional and Metabolic Activities in the Brain: A Systematic Review and Meta-Analysis of Functional Neuroimaging Studies.

Front. Neurosci. 15:684926 doi: 10.3389/fnins.2021.684926

\section{Effects of Chronic Pain Treatment on Altered Functional and Metabolic Activities in the Brain: A Systematic Review and Meta-Analysis of Functional Neuroimaging Studies}

\author{
Dongwon Kim ${ }^{1}$, Younbyoung Chae ${ }^{1,2}, \mathrm{Hi}$-Joon Park ${ }^{1,2}$ and In-Seon Lee ${ }^{1,2 *}$ \\ ${ }^{1}$ College of Korean Medicine, Kyung Hee University, Seoul, South Korea, ${ }^{2}$ Acupuncture and Meridian Science Research \\ Center, Kyung Hee University, Seoul, South Korea
}

Previous studies have identified altered brain changes in chronic pain patients, however, it remains unclear whether these changes are reversible. We summarized the neural and molecular changes in patients with chronic pain and employed a meta-analysis approach to quantify the changes. We included 75 studies and 11 of these 75 studies were included in the activation likelihood estimation (ALE) analysis. In the 62 functional magnetic resonance imaging (fMRI) studies, the primary somatosensory and motor cortex (SI and MI), thalamus, insula, and anterior cingulate cortex (ACC) showed significantly decreased activity after the treatments compared to baseline. In the 13 positron emission tomography (PET) studies, the SI, MI, thalamus, and insula showed significantly increased glucose uptake, blood flow, and opioid-receptor binding potentials after the treatments compared to baseline. A meta-analysis of fMRI studies in patients with chronic pain, during pain-related tasks, showed a significant deactivation likelihood cluster in the left medial posterior thalamus. Further studies are warranted to understand brain reorganization in patients with chronic pain compared to the normal state, in terms of its relationship with symptom reduction and baseline conditions.

Keywords: chronic pain, functional neuroimaging, activation likelihood estimation, meta-analysis, systematic review

\section{INTRODUCTION}

Pain is a highly complex and individual experience (https://www.iasp-pain.org/), which elicits behavioral, chemical, and neuronal responses throughout the body. Under normal conditions, acute and unfamiliar pain captures our attention, and the peripheral, autonomic, and central nervous system actively respond to painful stimuli and environments (Eccleston, 1994; Basbaum et al., 2009). As the detection and modulation of pain is critical for survival, individuals have developed a pain modulation system in the body by adjusting noxious input signals and cognitive modulation of the subjective pain experience, the so-called descending pain modulatory system (Tracey and Mantyh, 2007). Unfortunately, pain could last for significantly longer and become chronic in some patients, even though the injury and painful stimulation might disappear as patients receive conventional and effective treatments. 
In chronic pain conditions, defined as any pain persisting or recurring for longer than 3 months or more (Treede et al., 2015), abnormal structural, functional, and chemical changes in the periphery (e.g., sensitized peripheral receptors and nerve endings, elevated cytokine levels) (Fu et al., 2001; Wallace et al., 2001; Haroutounian et al., 2014), spinal cord (Pockett, 1995; Thomas Cheng, 2010), and brain (Apkarian et al., 2005; Smallwood et al., 2013) are related to our ability to cope with pain. A reduced threshold and excessive responsiveness to pain in the nociceptive pathway is known as central sensitization, which is a type of brain reorganization caused by neural plasticity, which leads to increased pain sensitivity (i.e., hyperalgesia) in chronic pain patients (Latremoliere and Woolf, 2009; Woolf, 2011). A significant number of studies have identified brain regions involved in the processing of acute and chronic pain, using functional neuroimaging techniques. They found an important role of the descending pain modulatory system, emotional circuitry, and learning, as well as anatomical and functional discrepancies in pain experience between healthy individuals and patients with chronic pain (Apkarian et al., 2005; Tracey and Mantyh, 2007; Henry et al., 2011; Bushnell et al., 2013). To summarize the body of evidence on the functional changes in patients with chronic pain, as compared to healthy participants, previous studies performed a meta-analysis using coordinate-based methods [e.g., activation likelihood estimation (ALE)]. For instance, Friebel et al. found that experimental painful stimulation administered to healthy participants evoked a significantly greater activation in the anterior/posterior insula, Rolandic operculum, supplementary motor area (SMA), and mid-cingulate cortex (MCC), and lesser activation in the caudal-anterior insula, anterior cingulate cortex (ACC), and supramarginal gyrus than chronic neuropathic pain conditions (Friebel et al., 2011). On the other hand, Lanz et al. found significant activation in the primary somatosensory cortex (SI), anterior/posterior insula, ACC, prefrontal cortex (PFC), thalamus, and cerebellum in healthy participants, compared to patients with neuropathic pain, and significant activation in the secondary somatosensory cortex (SII), SMA, and cerebellum in patients with neuropathic pain compared with healthy participants (Lanz et al., 2011). A more recent meta-analysis included 3,815 coordinates from functional magnetic resonance imaging (fMRI) studies applying painful cutaneous stimulation in healthy and chronic pain patients, revealing similar activation likelihood maps for healthy participants and patients with chronic pain, such as the SI, SII, thalamus, insula, cingulate cortex, PFC, basal ganglia, cerebellum, and brainstem (Tanasescu et al., 2016). The discrepant results of previous meta-analysis studies can be explained as a consequence of the heterogeneous samples and methodologies adopted across studies. Previous findings suggest that chronic pain affects the brain activity or patterns of activity in pain processing regions [which were originally referred to as the pain matrix (Talbot et al., 1991; Melzack, 2001; Duerden and Albanese, 2013)]. As chronic pain is not simply a feeling of pain for longer duration, its impact on the brain is not limited to the pain network. Instead, chronic pain is rather a complex experience which can alter many other functional networks such as corticolimbic (Baliki et al., 2012;
Mansour et al., 2013), salience (Qiu et al., 2015), somatosensorymotor, and default mode networks (Baliki et al., 2008a, 2014; Becerra et al., 2014), as well as cross-network connectivity between the networks (Hemington et al., 2016; Cottam et al., 2018).

Baliki and Apkarian suggested four distinct phases of development of chronic pain: pre-injury, injury, transition, and maintenance phase, arguing that chronic pain is a neurological disease (Baliki and Apkarian, 2015). They also proposed that someone who has a cortical risk factor (e.g., lowered threshold for conscious experience of pain in response to nociceptive inputs, anatomical properties of the corticolimbic circuitry) might have a greater propensity to developing chronic pain from acute pain (Baliki et al., 2012; Mansour et al., 2013; Baliki and Apkarian, 2015; Vachon-Presseau et al., 2016b). From this point of view, we can assume that untreated changes in the brain may result in a persistent pain cycle, and that the modulation of structural and functional changes in the brain may be a key to successful chronic pain management. Growing evidence points toward the clinical effectiveness of interventions targeting brain activity in patients, such as brain stimulation, hypnosis, and meditation (Jensen M. P. et al., 2014).

A few studies have shown that the effective treatment of chronic pain reverses functional and structural brain changes in patients with chronic pain. Gwilym et al. found that decreased gray matter volume in the thalamus returned to a level similar to that in healthy volunteers after hip surgery in patients with hip osteoarthritis (OA) (Gwilym et al., 2010). Ceko et al. found that functional connectivity and white matter in the insula were normalized after treatment (spine surgery or zygapophysial joint block), and that the degree of altered functional connectivity in the insula and dorsolateral PFC was significantly correlated with pain reduction in patients with chronic low back pain (Ceko et al., 2015). In addition to the functional and anatomical changes, the effects of pain treatment on the metabolic processes in chronic pain populations have been demonstrated using Positron Emission Tomography (PET). For example, PET studies have demonstrated the effects and mechanisms of neurostimulation techniques in neuropathic pain patients. Yoon et al. found that transcranial direct current stimulation (tDCS) on the primary motor cortex (MI) in neuropathic pain patients significantly reduced subjective pain scores. They showed that glucose metabolism was significantly decreased in the dorsolateral PFC, orbitofrontal cortex (OFC), and posterior cingulate cortex (PCC), and increased in the SI, insula, and ACC in the tDCS group than in the sham stimulation group (Yoon et al., 2014). Kishima et al. also found that spinal cord stimulation significantly reduced subjective pain ratings and increased cerebral blood flow in the thalamus, MI, ACC, and dorsolateral PFC after the treatment compared to baseline (Kishima et al., 2010). These findings provide evidence for clinical use of neurostimulation treatments in chronic pain patients and insights about their actions in the brain.

It has been discussed that substantial functional, structural, and molecular changes in the brain regions and networks are associated with many chronic pain conditions, and our brain may reorganize itself after treatment, as it did when it experienced 
chronic pain. However, it is still unclear which regions are adaptable and which are not, or which regions are showing consistent changes across various chronic pain conditions while other regions show heterogeneous changes which cannot be detectable by meta-analytic approach. To answer this question, we reviewed previous functional neuroimaging studies that examined functional and molecular activities altered by pain relief interventions, as a whole-brain meta-analysis was carried out on a subset of the included fMRI studies that studied painrelated tasks in patient populations with chronic pain. As we assumed that imaging conditions (resting-state fMRI, task-based fMRI, PET) and tasks (pain-related, motor, cognitive, etc.) were highly heterogeneous, we limited the meta-analysis to fMRI results measured during painful tasks (painful stimulation task or pain-related motor task) with whole-brain coordinate-level data (peak x, y, z coordinates, and anatomical template).

Our research question according to the Population, Intervention, Comparator and Outcome (PICO) protocol (Higgins et al., 2019) then is: in which brain regions functional and molecular brain activities in chronic pain patients, measured by functional neuroimaging techniques such as fMRI and PET, would show consistent and significant change, either increased or decreased by treatment of chronic pain. We assumed that changes of affected functional and metabolic activities are driven by reduced pain intensity and unpleasantness in chronic pain patients, since most functional neuroimaging studies have reported significant improvements in pain and successful pain relief should be warranted for further investigation of the neural mechanisms of interventions for chronic pain. On the other hand, improvements of reward systems and cognitive networks might vary across different types of diseases and interventions as higher cognitive functions are unlikely to be changed by pain relief. Based on the assumption, we hypothesized that the treatment of chronic pain can alter functional and metabolic activities in the brain regions, especially the hub of the pain-related networks, and such changes are more consistent within the regions associated with the affective and sensorydiscriminative components of pain (SI, MI, thalamus, ACC, and insula) than other regions involved in cognitive control and reward processing (limbic and frontal cortices).

\section{MATERIALS AND METHODS}

\section{Literature Search and Article Selection}

A systematic review was conducted, following the Preferred Reporting Items for Systematic Reviews and Meta-Analyses (PRISMA) guidelines (Moher et al., 2009). Both fMRI and PET studies in chronic pain patients were searched in the PubMed and fMRI data repository NeuroSynth (neurosynth.org) on $2^{\text {nd }}$ February 2020. We searched PubMed using chronic pain-related keywords [chronic pain, neuropathic, chronic back pain, fibromyalgia (FM), migraine, irritable bowel syndrome (IBS), and inflammatory bowel disease], neuroimaging-related keywords (fMRI, PET, and brain activation), and treatmentrelated keywords (treatment, intervention, medication, drug, acupuncture, etc.). Keywords for the NeuroSynth repository search included chronic pain diseases and their relevant terms such as chronic pain, neuropathic pain, chronic back pain, chronic low back pain, FM, migraine, IBS, inflammatory bowel disease, etc., and we did not restrict the search to certain diseases. References of the searched articles were reviewed manually.

Abstracts were reviewed by two reviewers (I. S. L and D. W. K) for inclusion. We predefined eligibility criteria following the PICO protocol (Higgins et al., 2019). Articles were considered eligible if they 1) included chronic pain patients (clearly describing that patients are suffering from 'chronic pain' or suffering from pain disease for more than 3 months), 2) administered any type of interventions (e.g., pharmacological drug, cognitive therapy, neural stimulation), 3) included functional neuroimaging measurements (e.g., restingstate or task-related fMRI, PET), and 4) investigated patients' brain activity at least twice, before and after the treatment (henceforth referred to as PRE and POST, respectively). As we were interested in the effects of pain treatments on functional and metabolic brain activities, we excluded studies that 1) did not precisely describe the duration of pain or diagnosis criteria, 2) included chronic pain patients during a period of remission, 3) combined neuroimaging results of patients with chronic pain and other diseases, and 4) administered a treatment once inside the scanner to observe the neural responses to the treatment. We restricted our search to publications in English.

\section{Data Extraction}

For the systematic review, we extracted the authors' name, year of publication, patient's information (disease, symptom duration, number, and age of patients), treatment, imaging condition (stimulus modality and task), and analysis method [whole-brain voxel-wise analysis, region of interest (ROI) analysis, multiple comparison correction methods, etc.]. Since the aim of this systematic review was to summarize functional changes in brain activities caused by effective treatment, we summarized treatment-induced significant changes in patients' brain functional activities and clinical outcomes, as well as reports of adverse events.

For the meta-analysis, we extracted the number of participants whose neuroimaging data were analyzed, activation (increased after the treatments in patients with chronic pain; POST > PRE) and deactivation (decreased after the treatments in patients with chronic pain; PRE $>$ POST) coordinates, along with their associated standard anatomical template.

\section{Activation Likelihood Estimation Analysis Whole-Brain Activation Likelihood Estimation (Pain-Related Tasks Only)}

A subset of fMRI studies for the systematic review was also included in the meta-analysis using ALE analysis. In addition to the preceding inclusion criteria for the systematic review, we included all fMRI studies if peak coordinates $(x, y$, and $z$ ) from whole-brain volume analyses and anatomical templates for both the PRE and POST contrasts were given. Due to the high heterogeneity of tasks in task-based fMRI studies, and methodological limitations of resting-state fMRI studies, only those fMRI studies that adopted pain-related tasks were considered for the meta-analysis. Pain-related tasks were defined 
as any stimulations or tasks related to painful somatic sensation in patients; for example, even tactile stimuli could be included if allodynia was induced in chronic pain patients. Resting-state fMRI studies and task fMRI studies that applied pain-related emotional tasks (e.g., fear) or non-pain-related tasks (e.g., not painful tactile stimulation) were excluded from the ALE metaanalysis. The given coordinates from the included fMRI studies were used to calculate statistical maps estimating the likelihood of activation for each voxel above chance levels.

We used GingerALE (Version 3.0.2, http://brainmap.org) and performed an ALE analysis on coordinates in Montreal Neurological Institute (MNI) space (Eickhoff et al., 2012). An ALE analysis is a widely used methodology for the coordinate-based meta-analysis of neuroimaging data, in which the probability that a voxel contains at least one activation focus is calculated for each voxel by pooling the coordinates of foci reported in a series of neuroimaging studies, and convoluting a 3D Gaussian kernel by sample size to all reported foci.

All coordinates were transformed into the MNI space using the conversion tool (Talairach to MNI) implemented in the GingerALE software. Next, the included coordinates were sorted according to whether they showed either increased or decreased activation. We conducted two meta-analyses for the increased and decreased activation foci post-treatment, as compared to the pre-treatment, separately. Statistical ALE maps were corrected by cluster-based thresholding for a Family-wise error (FWE) rate corrected $P<0.05$ at the cluster level using uncorrected $P<$ 0.001 at the voxel-level as a cluster-forming threshold. To set the null distribution, 1,000 permutation tests were performed. Due to the small number of included studies, foci, and patients, we did not perform sub-group analyses.

\section{Sensitivity Analysis}

We performed multiple sensitivity analyses to assess the generality of the ALE analysis results. First, we repeated the ALE analysis following the removal of studies with sample size $<10$ to address the bias introduced by small-study effects. Additional sensitivity analyses were conducted using the leave-one-out method as multiple ALE analyses were repeatedly performed by excluding a different study each time.

\section{RESULTS}

\section{Systematic Review}

Figure 1 represents the PRISMA flow diagram of the article search (Figure 1). A total of 1,606 publications were identified through PubMed and Neurosynth, and an additional six publications were identified by manual screening. After 34 duplicates were removed, 1,497 articles were excluded. We included 75 studies in the qualitative review, and 11 of these were included in the quantitative meta-analysis. Among the 75 included studies, 13 were PET studies, 37 were task-based fMRI studies, 21 were resting-state fMRI studies, and four studies reported both resting-state activities and task-related activities. The studies were divided according to the imaging conditions, and their details are summarized in Supplementary Tables 1-4.

\section{Clinical Outcomes and Adverse Events}

We summarized only the statistically significant clinical improvements in Supplementary Tables 1-4. Most of the studies reported significant improvements in pain response (spontaneous clinical pain, pain ratings to experimental painful stimulation, pain threshold/tolerance, pain attack time/day, tender point count, etc.) or pain-related emotional states (unpleasantness, fear, interference, etc.). In addition, symptoms unrelated to pain (e.g., defecation frequency and wrist function), depression, anxiety, quality of life, sleep quality, and medication use were evaluated using questionnaires and diaries. One study did not report any clinical outcome (Smallwood et al., 2016), and there were no significant differences in clinical outcomes between the PRE and POST visits in two studies (Petzke et al., 2013; Micalos et al., 2014). We also summarized whether they monitored and reported adverse events caused by the treatments for chronic pain. Among 75 studies, we found that 12 studies monitored and reported treatment-related adverse events (Walitt et al., 2007; Gustin et al., 2010; Tillisch et al., 2012; Petzke et al., 2013; Boyer et al., 2014; Li et al., 2015; Zhao et al., 2015, 2018; Zhang et al., 2016; Pinto-Sanchez et al., 2017; Privitera et al., 2017; Tetreault et al., 2018), and 7 studies monitored but did not report adverse events in the articles (Harris et al., 2013; Taylor et al., 2013; Jensen K. B. et al., 2014; Flodin et al., 2015; Sanders et al., 2015; Geha et al., 2016; Rogachov et al., 2019).

\section{Brain Changes by Treatment of Chronic Pain (fMRI Studies)}

The fMRI studies included in the present systematic review have been summarized in Supplementary Tables 1-3. Chronic pain conditions included FM $(n=15)$, neuropathic pain (post-stroke central pain, post-herpetic neuralgia, CRPS, cervical spondylosis neck pain, carpal tunnel syndrome, and amputation/phantom limb pain; $n=10)$, chronic low back pain $(n=9)$, headache/migraine $(n=8)$, chronic OA (knee or hand), IBS ( $n$ $=7$ ), chronic musculoskeletal pain, somatoform pain disorder, Crohn's disease, inflammatory bowel disease, erythromelalgia, and failed back surgery syndrome $(n=1)$.

The interventions employed in the studies included pharmacological treatments (sphenopalatine ganglion blockade, pregabalin, duloxetine, ketamine, lidocaine patch, etc.; $n=23)$, acupuncture or electro-acupuncture $(n=18)$, behavioral/cognitive/education/exercise therapy $(n=12)$, neurostimulation [tDCS, transcranial magnetic stimulation (TMS), and spinal cord stimulation; $n=5$ ], surgery or invasive intervention $(n=3)$, drug withdrawal, and moxibustion $(n=2)$.

For the task-based fMRI studies, 27 studies employed painrelated tasks such as spontaneous pain rating, receiving painful stimulation, and hand squeezing, while another 10 studies used non-pain-related tasks such as visual tasks and non-painful tactile stimulation during fMRI scanning. The most common analysis methods were ROI-based analyses $(n=20)$ and correlation analyses (mostly ROI-based correlation analysis between brain activity and clinical outcomes; $n=22$ ). Only a few studies applied a functional connectivity analysis (Napadow et al., 2007; Hashmi et al., 2012), principal component analysis, spectral 


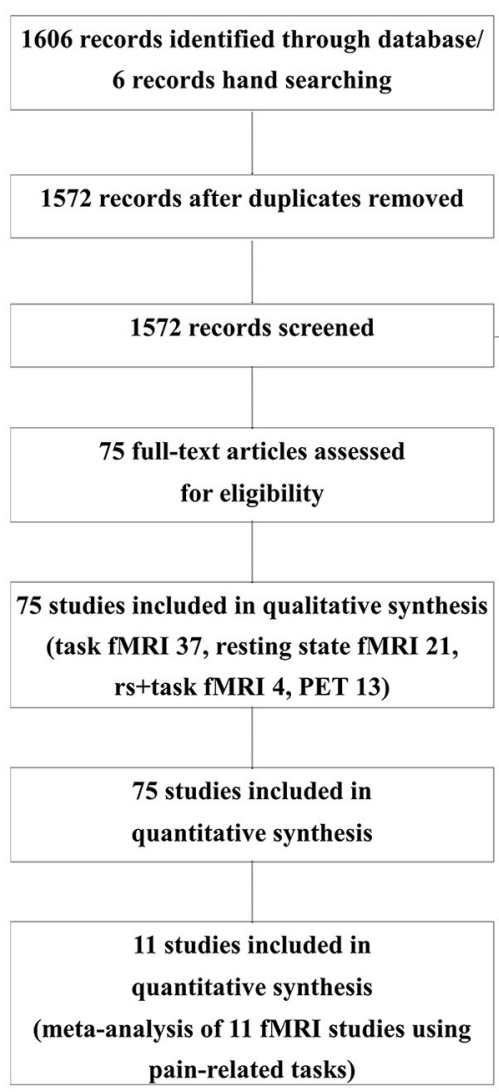

1497 full-text articles excluded:

-Not English ( $n=79)$

- Not experimental studies $(n=472)$

-Not human study $(n=137)$

- Not chronic pain related $(n=277)$

-Only part of patients had chronic pain $(n=1)$

-Not functional MRI/PET study $(n=162)$

-No treatment $(n=340)$

-No pre- and post-treatment neuroimaging

measurements $(n=29)$

FIGURE 1 | Flow diagram of literature search.

power analysis (Hashmi et al., 2012), and covariate analysis (Geha et al., 2007; Baliki et al., 2008b; Parks et al., 2011). For the analysis of resting-state fMRI, a functional connectivity analysis $(n=$ 16) and independent component analysis (ICA; $n=14$ ) were the most popular approaches, and amplitude of low frequency fluctuations (ALFF) or fractional ALFF (Shpaner et al., 2014; Li et al., 2017), multi-voxel pattern analysis/machine learning (Chen et al., 2018; Rogachov et al., 2019) ( $n=2)$, graph (Tetreault et al., 2018), and regional homogeneity analysis (Chen et al., 2018) ( $n$ $=1$ ) were also used. For the ICA, the default mode network was the most frequently targeted functional network (Napadow et al., 2012; Li et al., 2014; Shpaner et al., 2014; Yoshino et al., 2018; Rogachov et al., 2019; Zou et al., 2019) ( $n=5$ ); the salience, basal ganglia, fronto-parietal, sensorimotor, central-executive, and dorsal attention networks were also targeted.

The summarized results of the PRE vs. POST contrasts of fMRI studies in the pain processing regions are shown in Table 1. The SI ( 7 of 9 studies), MI (4 of 5 studies), and thalamus (5 of 6 studies) showed significantly decreased activity after treatment compared to the pre-treatment baseline. The ACC (increased $n$ $=3$, decreased $\mathrm{n}=6$ ) and insula (increased $n=5$, decreased $n$ $=8$ ) showed a trend of decrease. On the other hand, the trend of increase or decrease was not clear for the SII (increased $n=2$, decreased $n=2$ ), PCC (increased $n=3$, decreased $n=3$ ), PFC (increased $n=3$, decreased $n=5$ ), and OFC (increased $n=2$, decreased $n=1)$.

\section{Brain Changes by Treatment of Chronic Pain (PET Studies)}

A summary of the PET studies used in the present systematic review is presented in Supplementary Table 4. Patients with FM (Walitt et al., 2007; Harris et al., 2009; Boyer et al., 2014; Sawaddiruk et al., 2019), IBS (Berman et al., 2002; Mayer et al., 2002; Lieberman et al., 2004; Lackner et al., 2006) $(n=4)$, neuropathic pain (Maarrawi et al., 2007; Kishima et al., 2010; Yoon et al., 2014) ( $n=3$ ), headache (Magis et al., 2011), and chronic tennis elbow (Linnman et al., 2016) $(n=1)$ were included in the PET imaging studies. To treat chronic pain patients, neurostimulation (occipital nerve, spinal cord, tDCS/TMS, etc.; $n=5$ ), pharmacological treatment (alosetron, pregabalin, Coenzyme Q10; $n=3$ ), cognitive/exercise therapy $(n=2)$, acupuncture, individualized combination therapy, and placebo regimen $(n=1)$ were administered to patients with chronic pain. Using PET imaging technology, patients' glucose uptake, blood flow $(n=5)$, and opioid $(n=2)$ and neurokinin 1 receptor binding $(n=1)$ in the brain tissue were measured before and after the treatments. Positron emission tomography imaging scans were conducted during the rest $(n=8)$, visceral distention 
TABLE 1 | Summary of changes in functional activities (pre-treatment vs. post-treatment) in the fMRI studies.

\begin{tabular}{|c|c|c|c|c|c|c|c|c|c|c|c|}
\hline References (task) & Chronic pain & Treatment (duration) & SI & THAL & MI & INS & ACC & PCC & PFC & OFC & $\begin{array}{l}\text { SII/ } \\
\text { OPER }\end{array}$ \\
\hline $\begin{array}{l}\text { Jensen et al. (2012) } \\
\text { (pain) }\end{array}$ & $\mathrm{FM}$ & CBT (12w) & & & & $\uparrow$ & & & $\uparrow$ & $\uparrow$ & \\
\hline Kim et al. (2013) (pain) & $\mathrm{FM}$ & Pregabaline & & & & & & & & & \\
\hline $\begin{array}{l}\text { Koeppe et al. (2004) } \\
\text { (pain) }\end{array}$ & $\mathrm{FM}$ & Tropisetron/prilocaine & & & & & & & & & \\
\hline $\begin{array}{l}\text { Petzke et al. (2013) } \\
\text { (pain) }\end{array}$ & $\mathrm{FM}$ & Milnacipran & $\uparrow$ & $\uparrow$ & & $\uparrow$ & $\uparrow$ & $\uparrow$ & & & \\
\hline Taylor et al. (2013) (pain) & $\mathrm{FM}$ & $\begin{array}{l}\text { Cranial electrical stimulation } \\
(8 \mathrm{w})\end{array}$ & & & & $\uparrow$ & & & $\uparrow$ & & \\
\hline $\begin{array}{l}\text { Harte et al. (2016) } \\
\text { (visual) }\end{array}$ & $\mathrm{FM}$ & $\begin{array}{l}\text { Pregabalin } \\
\text { (17 days) }\end{array}$ & & & & & & & & & \\
\hline Harris et al. (2013) (pain) & $\mathrm{FM}$ & Pregabalin (2 w) & & & & & & & & & \\
\hline $\begin{array}{l}\text { Baliki et al. (2008b) } \\
\text { (pain) }\end{array}$ & LBP & $\begin{array}{l}\text { lidocaine patch } \\
(2 \mathrm{w})\end{array}$ & & & & & & & & & \\
\hline $\begin{array}{l}\text { Smallwood et al. (2016) } \\
\text { (pain) }\end{array}$ & LBP & $\begin{array}{l}\text { Acceptance-commitment } \\
\text { therapy/health education program } \\
(4 \mathrm{w})\end{array}$ & & & & & & & & & \\
\hline $\begin{array}{l}\text { Seminowicz et al. (2011) } \\
\text { (MSIT) }\end{array}$ & LBP & $\begin{array}{l}\text { Spine surgery or zygapophysial } \\
\text { joint injections }\end{array}$ & & & & & & & & & \\
\hline $\begin{array}{l}\text { Timmers et al. (2019) } \\
\text { (visual) }\end{array}$ & LBP & Exposure therapy & & & & & & & & & \\
\hline $\begin{array}{l}\text { Sanders et al. (2015) } \\
\text { (pain) }\end{array}$ & Hand OA & $\begin{array}{l}\text { Naproxen } \\
(1 \mathrm{w})\end{array}$ & & & & & & & & & \\
\hline $\begin{array}{l}\text { Shpaner et al. (2014) } \\
\text { (REST) }\end{array}$ & $\begin{array}{l}\text { Musculoskeletal } \\
\text { pain }\end{array}$ & $\begin{array}{l}\text { CBT } \\
(11 w)\end{array}$ & & & & & & $\uparrow$ & & & \\
\hline Chen et al. (2015) (ACU) & Knee OA & $\operatorname{ACU}(4 \mathrm{w})$ & & & & & & & & & $\uparrow$ \\
\hline Gustin et al. (2010) (pain) & $\begin{array}{l}\text { Neuropathic } \\
\text { pain (CRPS) }\end{array}$ & $\begin{array}{l}\text { NMDA-REC antagonist, morphine } \\
(7-8 \mathrm{w})\end{array}$ & & & & & & & & & \\
\hline Geha et al. (2007) (pain) & $\begin{array}{l}\text { Neuropathic pain } \\
\text { (post-herpetic } \\
\text { neuralgia) }\end{array}$ & $\begin{array}{l}\text { Lidocaine } \\
(2 \mathrm{w})\end{array}$ & & & & $\uparrow$ & & & & & \\
\hline $\begin{array}{l}\text { Napadow et al. (2007) } \\
\text { (ACU) }\end{array}$ & $\begin{array}{l}\text { Neuropathic pain } \\
\text { (CTS) }\end{array}$ & $\begin{array}{l}\mathrm{ACU} \\
(5 \mathrm{w})\end{array}$ & $\uparrow$ & & & $\uparrow$ & $\uparrow$ & & $\uparrow$ & & \\
\hline Grazzi et al. (2010) (pain) & $\begin{array}{l}\text { Migraine with } \\
\text { medication } \\
\text { overuse }\end{array}$ & $\begin{array}{l}\text { Drug withdrawal } \\
(6 \mathrm{~m})\end{array}$ & & & & & & & & & \\
\hline Li et al. (2017) (REST) & $\begin{array}{l}\text { Migraine without } \\
\text { aura }\end{array}$ & $\begin{array}{l}\mathrm{ACU} \\
(4 \mathrm{~W})\end{array}$ & & & & & & & & $\uparrow$ & \\
\hline
\end{tabular}




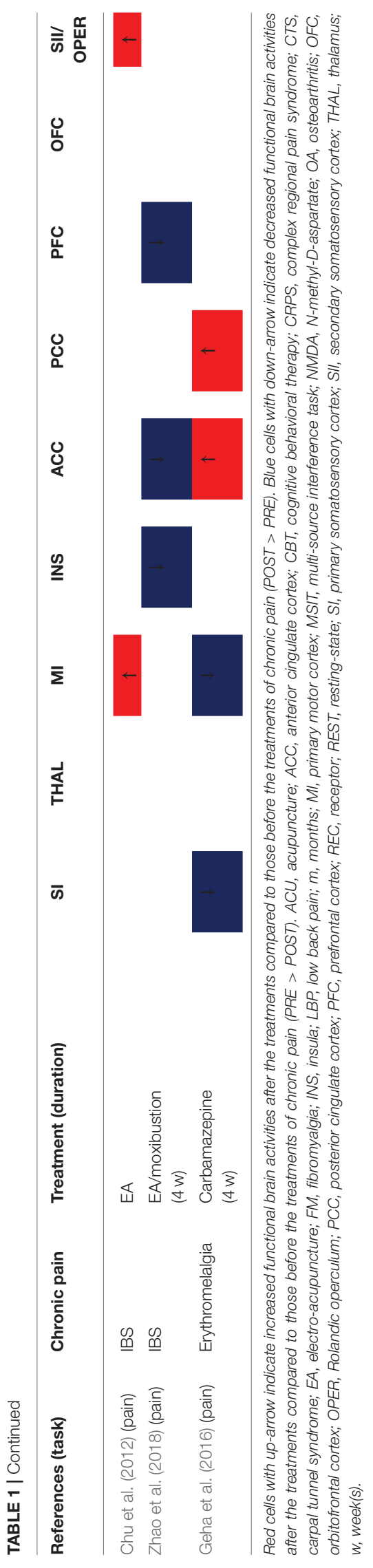

$(n=4)$, and treatment interventions (occipital neurostimulation and acupuncture; $n=1$, respectively). Whole-brain analysis ( $n=$ $12)$, ROI-based analysis $(n=8)$, and correlation analysis $(n=4)$ were the most popular analysis methods for PET imaging studies.

A summary of PRE vs. POST results of PET studies, in which either the whole-brain or regions (volumes) of interest analysis was used, in the pain processing regions is presented in Table 2. The SI, MI, thalamus, and insula showed significantly increased tissue glucose uptake, blood flow, and $\mu$-opioid receptor binding potentials after the treatments, compared to the pre-treatment baseline, while PCC showed significantly decreased glucose uptake and blood flow. Two PET studies showed that the blood flow was increased in the insula, and decreased in the ACC, in response to painful stimulation after the treatment compared to the baseline (Berman et al., 2002; Mayer et al., 2002). The SII did not show significant changes between the PRE and POST conditions in PET imaging studies.

\section{Whole-Brain ALE Meta-Analysis of Pain-Related Task fMRI Studies Significant Clusters for After Treatment vs. Baseline Contrast During Pain Tasks}

For the coordinate based meta-analysis of whole-brain fMRI studies, 118 activation and deactivation foci were extracted from 11 pain-related fMRI studies in 256 chronic pain patients (222 female). Chronic pain conditions included FM $(n=4)$, neuropathic pain (post-herpetic neuralgia, CRPS; $n=2$ ), chronic OA (knee or hand; $n=2$ ), chronic low back pain, irritable bowel disease, and erythromelalgia $(n=1)$. Since the aim of the coordinate-based ALE analysis was to identify brain regions that are significantly modulated by pain treatments, we included the significantly activated or deactivated foci separately during the pain tasks extracted from the PRE vs. POST contrasts. The painrelated tasks in fMRI studies included in the meta-analysis were spontaneous pain rating, movement of the paining body parts (e.g., hand squeezing), and receiving painful stimulation tasks (painful thermal, cold, and mechanical stimulation including rectal distention).

There were no significantly activated foci that survived a multiple comparison correction (PRE $<$ POST during pain tasks). The likelihood of deactivation was significant after a multiple comparison correction in the left medial posterior thalamus ( $x=-6, y=24, z=0 ; p<0.001$, Figure 2B), pointing thereby to a significant probability of deactivation in the medial posterior thalamus in response to pain-related tasks after the treatment compared to the pre-treatment states (POST $<$ PRE during pain tasks). The left thalamus, caudate, globus pallidus, BA 18 (lingual gyrus), and right BA 30 (parahippocampal gyrus), putamen, and BA 31 (cingulate gyrus) were also deactivated at uncorrected $p<0.001$ and extent threshold $k>30$ (Figure 2A).

\section{Sensitivity Analysis}

Four studies had small sample sizes $(n<10)$ (Koeppe et al., 2004; Baliki et al., 2008b; Kim et al., 2013; Geha et al., 2016), and the results of the ALE analysis after removal of these studies did not survive FWE correction $(P<0.05$ at cluster-level and uncorrected $P<0.001$ at voxel-level, $k>30$ ). According to the 
TABLE 2 | Summary of metabolic changes (pre-treatment vs. post-treatment) in the PET studies

\begin{tabular}{|c|c|c|c|c|c|c|c|c|c|c|c|}
\hline $\begin{array}{l}\text { References (task, } \\
\text { analysis) }\end{array}$ & Chronic pain & Treatment (duration) & SI & THAL & MI & INS & ACC & PCC & PFC & OFC & $\begin{array}{l}\text { SII/ } \\
\text { OPER }\end{array}$ \\
\hline $\begin{array}{l}\text { Walitt et al. (2007) } \\
\text { (REST, VOIs) }\end{array}$ & FM & $\begin{array}{l}\text { Individualized, } \\
\text { comprehensive (8 w) }\end{array}$ & & Glu $\uparrow$ & & Glu $\uparrow$ & & & & Glu $\uparrow$ & \\
\hline $\begin{array}{l}\text { Magis et al. (2011) } \\
\text { (occipital nerve } \\
\text { stimulation, ROls) }\end{array}$ & $\begin{array}{l}\text { Drug-resistant } \\
\text { chronic cluster } \\
\text { headache }\end{array}$ & $\begin{array}{l}\text { Occipital nerve } \\
\text { stimulation (various) }\end{array}$ & Glu $\uparrow$ & & Glu $\uparrow$ & & & & & & \\
\hline $\begin{array}{l}\text { Yoon et al. (2014) } \\
\text { (REST, whole-brain) }\end{array}$ & Neuropathic pain & $\begin{array}{l}\text { tDCS on the MI (10 } \\
\text { days) }\end{array}$ & Glu $\uparrow$ & & & Glu $\uparrow$ & Glu $\uparrow$ & & & & \\
\hline $\begin{array}{l}\text { Berman et al. (2002) } \\
\text { (pain, whole-brain, } \\
\text { ROls) }\end{array}$ & IBS & Alosteron (3w) & & & & Blood flow $\uparrow$ & odf & & & & \\
\hline $\begin{array}{l}\text { Mayer et al. (2002) } \\
\text { (pain, ROIs) }\end{array}$ & IBS & Alosteron (3w) & & & & Blood flow $\uparrow$ & od flc & & Blood flow 1 & & \\
\hline $\begin{array}{l}\text { Lackner et al. (2006) } \\
\text { (REST, whole-brain) }\end{array}$ & IBS & $\begin{array}{l}\text { Cognitive therapy } \\
(10 w)\end{array}$ & & & & & od fle & & & & \\
\hline $\begin{array}{l}\text { Kishima et al. (2010) } \\
\text { (REST, whole-brain) }\end{array}$ & Neuropathic pain & $\begin{array}{l}\text { Spinal cord stimulation } \\
(>6 \mathrm{~m})\end{array}$ & & Blood flow & Blood flow $\uparrow$ & & Blood flow $\uparrow$ & & Blood flow 1 & 3lood flow & \\
\hline $\begin{array}{l}\text { Maarrawi et al. (2007) } \\
\text { (REST, VOIs) }\end{array}$ & Neuropathic pain & $\begin{array}{l}\text { Motor cortex } \\
\text { stimulation } \\
(7 \mathrm{~m})\end{array}$ & & & & & & & & & \\
\hline $\begin{array}{l}\text { Harris et al. (2009) } \\
\text { (ACU, ROls) }\end{array}$ & $\mathrm{FM}$ & $\mathrm{ACU}(4 \mathrm{w})$ & & $\begin{array}{c}\imath \text {-opioid RE } \\
\uparrow\end{array}$ & & $\begin{array}{c}\text { l-opioid REC } \\
\uparrow\end{array}$ & $\begin{array}{c}\mu \text {-opioid REC } \\
\uparrow\end{array}$ & & & & \\
\hline
\end{tabular}

Red cells with up-arrow indicate increased measures of PET scans (e.g., glucose uptake, receptor bindings, etc.) after the treatments compared to those before the treatments of chronic pain (POST > PRE). Blue cells with down-arrow indicate decreased measured PET scans after the treatments compared to those before the treatments of chronic pain (PRE > POST). ACU, acupuncture; ACC, anterior cingulate cortex; FM, fibromyalgia; Glu, glucose; IBS, irritable bowel syndrome; INS, insula; LBP, low back pain; m, months; the MI, primary motor cortex; OFC, orbitofrontal cortex; OPER, Rolandic operculum; PCC, posterior cingulate cortex; PFC, prefrontal cortex; REC, receptor; REST, resting-state; ROIs, regions of interest; SI, primary somatosensory cortex; SII, secondary somatosensory cortex; tDCS, transcranial direct current stimulation; THAL, thalamus; VOIs, volumes of interest; w, week(s). 


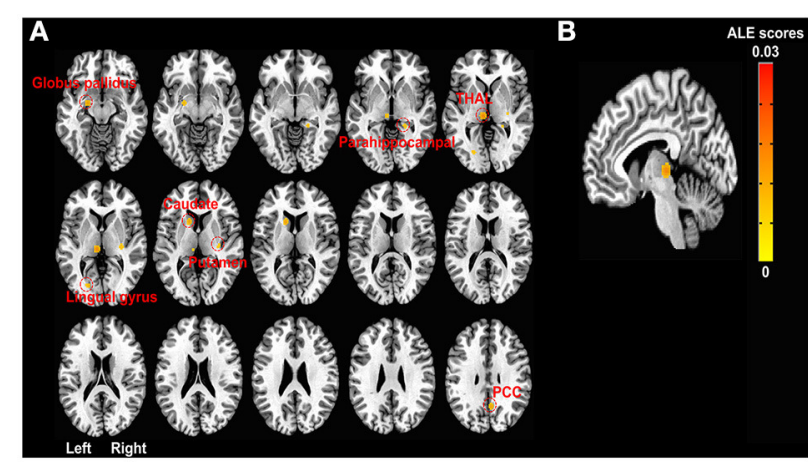

FIGURE 2 | ALE meta-analyses of $\mathrm{fMRI}$ studies in chronic pain patients during pain-related tasks. (A) Activation likelihood map showing seven deactivation clusters at uncorrected $p<0.001$ and extent threshold $k>30$. Deactivation clusters include the left thalamus $(-6,24,0$; 99 voxels), caudate $(-14,-14,8$; 55 voxels), globus pallidus (-20, 6, -12; 51 voxels), lingual gyrus (-20, 76, 2; 31 voxels), and right parahippocampal gyrus (22, 38, -4 ; 30 voxels), putamen (30, 22, 2; 36 voxels), and posterior cingulate gyrus (6, 58, 32; 52 voxels) after the chronic pain treatments compared to baseline (before the treatments) while patients with chronic pain were performing pain-related tasks (e.g., hand squeezing) or receiving painful stimulation. All clusters of activation (increased activation likelihood scores after pain treatments than before the treatments) at the uncorrected threshold were smaller than the minimum cluster size $(k>30)$. (B) FWE rate corrected activation likelihood map showing the significant deactivation cluster in the left medial posterior thalamus (-6, 24, 0; 99 voxels) after the chronic pain treatments compared to the baseline (before the treatments) while chronic pain patients were performing pain-related tasks (e.g., hand squeezing) or receiving painful stimulation $(P<0.05$ at cluster-level and uncorrected $P<0.001$ at voxel-level, $k>30$ ). Seven out of ten leave-one-out sensitivity analyses also showed a significantly decreased likelihood of activation in the left thalamus (FWE corrected as above, cluster sizes range 99-100). No clusters of activation passed the multiple comparison correction threshold. ALE, activation likelihood estimation; FWE, Family-wise error; PCC, posterior cingulate cortex; THAL, thalamus.

leave-one-out sensitivity analysis, 7 out of 10 ALE analyses on coordinates of deactivation foci showed a significantly decreased likelihood of activation in the left thalamus (FWE corrected as above, cluster sizes range 99-100). No activation foci survived a multiple comparison correction in any of the leave-one-out sensitivity analyses.

\section{DISCUSSION}

Becerra et al. defined the effect of treatment by comparing brain activities in patients with severe pain before treatment with those experiencing less pain after treatment. They also depicted the residual effect after treatment, which means the remaining differences in neural properties between patients with chronic pain and healthy controls (Becerra et al., 2014). To the best of our knowledge, this is the first systematic review and metaanalysis study to determine which brain regions show changes in their functions and metabolic states (the treatment effect), and which regions show remaining alterations (the residual effect) after chronic pain treatment.

In the neuroimaging studies comparing pre- and posttreatment conditions, task-based fMRI is the most frequently applied imaging technique, followed by resting-state fMRI scanning and PET imaging. In addition to the significant improvements in pain intensity or pain-related emotional states, psychological states (depression, anxiety), quality of life, and medication use were also evaluated. Among 75 studies, only 12 studies monitored and reported treatment-related adverse events. A meta-analysis of clinical outcomes was not performed since there were only few randomized controlled trials, and the data necessary to determine the effect size was not reported in most of the studies. Although clinical neuroimaging studies have been focusing on the changes of brain activities, however, we argue that we should improve the quality of reporting of clinical and behavioral data including adverse events. For example, there are discrepancies between samples from whom neuroimaging and clinical data were collected. Clinical outcomes were often measured using different types of questionnaires or scales, although heterogeneity of the included studies also contributed to the heterogeneous clinical measurements, and it makes us impossible to quantitatively summarize the results across the studies. Although only a few studies provided relevant data, we assessed the publication bias and heterogeneity using available data from 11 studies and found that there's a significant positive publication bias (Egger's regression $t=11.08, p<0.001$ ) and moderate heterogeneity $\left(I^{2}=58.73 \%\right)$. They suggest that the intervention effects were overestimated or there might be a positive reporting bias, and caution is needed in interpreting clinical results of the neuroimaging studies due to an insufficient number of treatment sessions and lack of an appropriate control group or intervention.

We found a tendency of decreased functional activities (in the SI, MI, thalamus, insula, and ACC) and increased molecular activities in the sensory-discriminative and affective regions (glucose consumption in the SI, glucose consumption and blood flow in the MI, glucose consumption, blood flow, and $\mu$-opioid receptor binding potential in the thalamus and insula) after the treatments than before the treatments of chronic pain, while other regions involved in reward and cognitive processes (amygdala, PFC, OFC, etc.) yielded inconsistent results across the studies. If we assume that these changes are associated with pain relief, decreased functional activities might indicate recovery from the sensitized response to pain-related tasks by the treatments. On the other hand, molecular activities in the SI, MI, thalamus, and insula might be elevated during the resting and pain conditions. The results suggest that successful pain treatments reduced processing of pain-related information and boosted the metabolic functions of the brain, so that the altered functional activities could be reversed while processing sensory-discriminative and affective components of pain. On the other hand, the regions involved in cognitive execution and reward processing functions might be less adjustable in response to pain treatments, as the complicated and higher cognitive functions might be treated neither consistently nor completely in the included studies. Further studies would be required to substantiate this inference.

The multiple-comparison-corrected ALE analysis showed a significantly decreased likelihood of activation in the left medial posterior thalamus during pain-related tasks in chronic pain 
patients after treatment than before treatment (the treatment effect), which suggests that the thalamus, especially the medial posterior part, is the most consistent region affected by pain treatments in patients with chronic pain. The thalamus is the transmission center of acute noxious signals from peripheral receptors to the cortex (e.g., SI and insula) through spinothalamic track, and also plays an important role in pain modulation and chronification. Pain modulatory effects of thalamus stimulation have been tested since the 1970s (Hosobuchi et al., 1973; Mayer and Liebeskind, 1974; Mazars, 1975; Rhodes and Liebeskind, 1978; Kupers et al., 2000), and thalamic stimulation influences the cerebral blood flow in the insula (Duncan et al., 1998), PAG, PFC (Kupers et al., 2000), and ACC (Davis et al., 2000). According to previous meta-analyses, the evidence of functional activities in the thalamus in patients with chronic pain compared to healthy controls is conflicting. Lanz et al. (2011) and Jensen et al. (2016) found that the thalamus was activated by pain tasks in both healthy and affected patients, and the healthy controls showed significantly stronger activity in the thalamus compared to the patients during pain experience. They considered, as such, that decreased activation likelihood in the thalamus may support decreased sensory processing in patients with chronic pain due to the continuous noxious input to the brain, and thalamic disturbances may lead to chronic pain symptoms. Since not all fMRI studies that reported PRE vs. POST contrasts reported them separately for patients and control groups, we could not conclude whether the decreased activation likelihood in the thalamus after the treatments is due to the increased activity in the thalamus during pain processing before the treatments (as we discussed above) or not. We also cannot neglect the fact that functional activities were actually decreased in the thalamus during pain processing in patients with chronic pain than in healthy controls, as shown in a previous meta-analysis, and that these activities might be decreased further after treatment, as our study showed. If so, it suggests that the functional activities in the thalamus may not return to a normal state and may only change upon treatment to a new state.

The thalamus, ACC, and insula constitute the salience and central autonomic network as well as the pain network (Lee et al., 2020), and they are also commonly activated during tasks related to non-painful stimulation, emotion, memory, and interoception (Cauda et al., 2012). Thus, decreased likelihood of activation in the thalamus and a tendency of decreased functional activities in the insula and ACC might be not solely related to the reduced pain sensations, but they might be also associated with the reduced salience processing. As there is an active debate about the pain specificity in the brain, please see Legrain et al. (2011), Mouraux and Iannetti (2018), and Lee et al. (2020) for more discussion.

Growing evidence demonstrates that chronic pain is not a longer-lasting form of acute pain. Rather, chronic pain has distinct mechanisms and mediators than acute pain in healthy population, albeit with some overlap, and various factors contribute to chronic pain such as psychological (VachonPresseau et al., 2016a; Hruschak and Cochran, 2018), molecular, structural, and functional neural mechanisms (Davis and Moayedi, 2013; Bliss et al., 2016; Taylor et al., 2016; Groh et al.,
2018; Adebiyi et al., 2019). It has been argued that chronic pain is a disease, in particular, a brain disease (Tracey and Bushnell, 2009; Davis and Moayedi, 2013), and not just a pain symptom left untreated or under-treated (Raffaeli and Arnaudo, 2017) [see Cohen et al. (2013) and Sullivan et al. (2013) for the opposite opinions, and it is noteworthy that we should also consider various chronic pain subgroups when dealing with this issue (Treede et al., 2019)]. If untreated changes in the brain result in a persistent pain cycle, the reversal of altered brain structural and functional changes toward a normal state may contribute to the relief of chronic pain. It is also plausible that chronic pain relief can normalize structural, functional, and metabolic abnormalities in the brain. Although we cannot assess the direction of effects between "normalized brain" and "reduced pain" in this study, this will be an interesting topic for further research to estimate the influence of pain reduction over brain changes, and the influence of the brain alterations on symptom improvement.

A survey of patients with chronic pain in Europe showed that one-third of the patients were currently not being treated; only $2 \%$ of them were currently treated by a pain specialist, and $40 \%$ were receiving inadequate pain management (Breivik et al., 2006). Moreover, oral analgesics, one of the fastest and cheapest medications for pain treatment, are not suitable for long-term pain relief due to side effects, and patients' tolerance to opioids is increasing, which means that the dose needs to be increased over time to achieve a certain amount of pain relief (Hylands-White et al., 2017). Recently, chronic pain treatment, which targets neural abnormalities in patients, has been receiving more attention (Borsook et al., 2007; Bentley et al., 2016) along with the advancement of pharmacological fMRI (investigating the effects of pharmacological interventions on functional brain changes) (Duff et al., 2015; Bauch et al., 2017) and increasing efforts to search for brain markers for pain in the brain (Wager et al., 2013; Duff et al., 2015; Lopez-Sola et al., 2017). Although this study only covers central functional and metabolic changes in chronic patients, our approach is important for identifying neural targets for chronic pain treatment. Identifying brain regions responding to the treatment offers valuable insight for the development of neural markers of diseases (e.g., markers for disease and symptom severity) and treatment effects (e.g., markers for symptom improvement of a certain treatment). For example, $\mu$-opioid receptor binding potentials were significantly increased in the dorsolateral PFC, ACC, thalamus, amygdala, putamen, and nucleus accumbens after treatment than before treatment, and binding potentials were significantly correlated with clinical pain ratings (Harris et al., 2009), which implies that the $\mu$-opioid receptor binding potentials are a strong candidate for chronic pain markers. In addition, intervention-related and disease-related functional and metabolic changes induced by intervention in a single subject will contribute to personalized pain management, as pain is an individual experience originating from the neuropathological state of the brain. We can estimate the effect of chronic pain in the brain, and also estimate and reevaluate the treatment effects focusing on neural changes using neuroimaging techniques. If we combine multiple neuroimaging techniques and measure various changes in the brain, such as 
structural, functional, and metabolic changes, we could develop a marker for chronic pain as well as a marker for the treatment effect, in the future. Questions related to future pain management will include "which treatment is more effective in alleviating hyper-sensitized thalamic response to painful stimulation?," "where should we target in the brain to reduce spontaneous pain?", and "which chronic pain disease is more likely to be treated by central manipulation (e.g., TMS) on the motor cortex?"; our approach may provide preliminary answers to the questions.

This study has a number of limitations. As we strictly restricted our analysis to the effects of chronic pain interventions, and did not include functional neuroimaging studies that did not involve chronic pain treatment, only a small number of studies were included in our ALE meta-analysis. A cautious interpretation of the results of the present study is necessary as underpowered studies have increased risk of false positives (Button et al., 2013). Previous meta-analysis studies may be referred to with regard to brain activation during painful stimulation in patients with chronic pain, irrelevant to the effect of treatment, corresponding (but not equivalent) to the PRE contrast in this study (Friebel et al., 2011; Lanz et al., 2011; Tanasescu et al., 2016). As participants of included studies had different diseases with different pathophysiology, our results need further validation. Moreover, they were treated by various interventions and few studies had small sample sizes, and most of the included studies were carried out only in adult populations (over 20 years old). All of these restrict generalizability of the results. Thus, we are not arguing that all chronic pain diseases have a single common mechanism, or that we could generalize the results to a larger population or apply them to a specific disease and intervention. Instead, our finding suggests that there might be a hub region in the brain which remains malleable in response to pain treatment, so that it can adapt itself to changes in the pain state. We need further investigation to clarify whether these changes are causally induced by pain relief or not, and whether the changes we found are similar or different across pain conditions. Moreover, due to methodological constraints, we were not able to measure the relationship between the degree of the treatment effect (the amount of pain reduction) and the degree of functional and metabolic changes in the brain. A metaanalysis of resting-state fMRI studies was technically available (Zang et al., 2015); however, we did not conduct the metaanalysis by combining heterogeneous statistical outcomes (ALFF, regional homogeneity, functional connectivity, etc.) as it might provide false information.

Based on the limitations of our study, we make following suggestions which can benefit future research. We suggest that clinical changes and adverse events should be monitored and reported in detail in future studies, as treatments should be effective and safe, and functional neuroimaging studies are no exception to this point. To analyze the relationship between the treatments and outcomes (e.g., pain intensity, pain interference, psychological state, quality of life, etc.) accurately, we need a standard guideline for reporting clinical outcomes in neuroimaging studies. Lastly, future study should further investigate "how" and "which factors" facilitate the changes of functional and molecular neural activities in chronic pain patients after treatment.

\section{CONCLUSION}

A systematic review of 62 fMRI and 13 PET studies showed the functional (decreased functional activities) and metabolic changes (increased glucose uptake, blood flow, $\mu$-opioid receptor binding potentials) in the somatosensory-discriminative regions (SI and thalamus) and the MI after the treatment of chronic pain compared to the pre-treatment baseline. Meta-analysis of 11 pain-related task fMRI studies showed that the activation likelihood in the thalamus was significantly decreased after the treatment compared to before the treatment. Our findings might help us develop a new treatment for chronic pain management that focuses on neural reorganization and allow for personalized treatment of chronic pain by considering diseasespecific, intervention-specific, and individual-specific responses in patients with chronic pain in the future.

\section{DATA AVAILABILITY STATEMENT}

Data are available upon request to the corresponding author.

\section{AUTHOR CONTRIBUTIONS}

DK and I-SL carried out the data extraction and meta-analysis, prepared the first draft. YC and H-JP interpreted the data. ISL finalized the manuscript. YC, H-JP, and I-SL performed the critical revision of the manuscript for important intellectual content. All authors contributed to the article and approved the submitted version.

\section{FUNDING}

This work was supported by the National Research Foundation of Korea (NRF) grant funded by the Korean government (MSIT) (NRF-2020R1A4A1018598, 2021R1F1A1050116). DK was supported by the Undergraduate Research Program (URP) grant funded by College of Korean Medicine, Kyung Hee University.

\section{SUPPLEMENTARY MATERIAL}

The Supplementary Material for this article can be found online at: https://www.frontiersin.org/articles/10.3389/fnins. 2021.684926/full\#supplementary-material 


\section{REFERENCES}

Adebiyi, M. G., Manalo, J., Kellems, R. E., and Xia, Y. (2019). Differential role of adenosine signaling cascade in acute and chronic pain. Neurosci. Lett. 712:134483. doi: $10.1016 /$ j.neulet.2019.134483

Apkarian, A. V., Bushnell, M. C., Treede, R. D., and Zubieta, J. K. (2005). Human brain mechanisms of pain perception and regulation in health and disease. Eur. J. Pain 9, 463-484. doi: 10.1016/j.ejpain.2004.11.001

Baliki, M. N., and Apkarian, A. V. (2015). Nociception, pain, negative moods, and behavior selection. Neuron 87, 474-491. doi: 10.1016/j.neuron.2015.06.005

Baliki, M. N., Geha, P. Y., Apkarian, A. V., and Chialvo, D. R. (2008a). Beyond feeling: chronic pain hurts the brain, disrupting the default-mode network dynamics. J. Neurosci. 28, 1398-1403. doi: 10.1523/JNEUROSCI.4123-07.2008

Baliki, M. N., Geha, P. Y., Jabakhanji, R., Harden, N., Schnitzer, T. J., and Apkarian, A. V. (2008b). A preliminary fMRI study of analgesic treatment in chronic back pain and knee osteoarthritis. Mol Pain 4:47. doi: 10.1186/1744-8069-4-47

Baliki, M. N., Mansour, A. R., Baria, A. T., and Apkarian, A. V. (2014). Functional reorganization of the default mode network across chronic pain conditions. PLoS ONE 9:e106133. doi: 10.1371/journal.pone.0106133

Baliki, M. N., Petre, B., Torbey, S., Herrmann, K. M., Huang, L., Schnitzer, T. J., et al. (2012). Corticostriatal functional connectivity predicts transition to chronic back pain. Nat. Neurosci. 15, 1117-1119. doi: 10.1038/ nn. 3153

Basbaum, A. I., Bautista, D. M., Scherrer, G., and Julius, D. (2009). Cellular and molecular mechanisms of pain. Cell 139, 267-284. doi: $10.1016 /$ j.cell.2009.09.028

Bauch, E. M., Andreou, C., Rausch, V. H., and Bunzeck, N. (2017). Neural habituation to painful stimuli is modulated by dopamine: evidence from a pharmacological fMRI study. Front. Hum. Neurosci. 11:630. doi: $10.3389 /$ fnhum.2017.00630

Becerra, L., Sava, S., Simons, L. E., Drosos, A. M., Sethna, N., Berde, C., et al. (2014). Intrinsic brain networks normalize with treatment in pediatric complex regional pain syndrome. Neuroimage Clin. 6, 347-369. doi: 10.1016/j.nicl.2014.07.012

Bentley, L. D., Duarte, R. V., Furlong, P. L., Ashford, R. L., and Raphael, J. H. (2016). Brain activity modifications following spinal cord stimulation for chronic neuropathic pain: a systematic review. Eur. J. Pain 20, 499-511. doi: 10.1002/ejp.782

Berman, S. M., Chang, L., Suyenobu, B., Derbyshire, S. W., Stains, J., Fitzgerald, L., et al. (2002). Condition-specific deactivation of brain regions by 5-HT3 receptor antagonist alosetron. Gastroenterology 123, 969-977. doi: 10.1053 /gast.2002.35990

Bliss, T. V., Collingridge, G. L., Kaang, B. K., and Zhuo, M. (2016). Synaptic plasticity in the anterior cingulate cortex in acute and chronic pain. Nat. Rev. Neurosci. 17, 485-496. doi: 10.1038/nrn.2016.68

Borsook, D., Moulton, E. A., Schmidt, K. F., and Becerra, L. R. (2007). Neuroimaging revolutionizes therapeutic approaches to chronic pain. Mol. Pain 3:25. doi: 10.1186/1744-8069-3-25

Boyer, L., Dousset, A., Roussel, P., Dossetto, N., Cammilleri, S., Piano, V., et al. (2014). rTMS in fibromyalgia: a randomized trial evaluating QoL and its brain metabolic substrate. Neurology 82, 1231-1238. doi: 10.1212/WNL.0000000000000280

Breivik, H., Collett, B., Ventafridda, V., Cohen, R., and Gallacher, D. (2006). Survey of chronic pain in Europe: prevalence, impact on daily life, and treatment. Eur. J. Pain 10, 287-333. doi: 10.1016/j.ejpain.2005.06.009

Bushnell, M. C., Ceko, M., and Low, L. A. (2013). Cognitive and emotional control of pain and its disruption in chronic pain. Nat. Rev. Neurosci. 14, 502-511. doi: $10.1038 / \mathrm{nrn} 3516$

Button, K. S., Ioannidis, J. P., Mokrysz, C., Nosek, B. A., Flint, J., Robinson, E. S., et al. (2013). Power failure: why small sample size undermines the reliability of neuroscience. Nat. Rev. Neurosci. 14, 365-376. doi: 10.1038/nrn3475

Cauda, F., Torta, D. M., Sacco, K., Geda, E., D’agata, F., Costa, T., et al. (2012). Shared "core" areas between the pain and other task-related networks. PLoS ONE 7:e41929. doi: 10.1371/journal.pone.0041929

Ceko, M., Shir, Y., Ouellet, J. A., Ware, M. A., Stone, L. S., and Seminowicz, D. A. (2015). Partial recovery of abnormal insula and dorsolateral prefrontal connectivity to cognitive networks in chronic low back pain after treatment. Hum. Brain Mapp. 36, 2075-2092. doi: 10.1002/hbm.22757
Chen, J., Wang, Z., Tu, Y., Liu, X., Jorgenson, K., Ye, G., et al. (2018). Regional homogeneity and multivariate pattern analysis of cervical spondylosis neck pain and the modulation effect of treatment. Front. Neurosci. 12:900. doi: 10.3389 /fnins.2018.00900

Chen, X., Spaeth, R. B., Freeman, S. G., Scarborough, D. M., Hashmi, J. A., Wey, H. Y., et al. (2015). The modulation effect of longitudinal acupuncture on resting state functional connectivity in knee osteoarthritis patients. Mol. Pain 11:67. doi: 10.1186/s12990-015-0071-9

Chu, W. C., Wu, J. C., Yew, D. T., Zhang, L., Shi, L., Yeung, D. K., et al. (2012). Does acupuncture therapy alter activation of neural pathway for pain perception in irritable bowel syndrome? A comparative study of true and sham acupuncture using functional magnetic resonance imaging. J. Neurogastroenterol. Motil. 18, 305-316. doi: 10.5056/jnm.2012.18.3.305

Cohen, M., Quintner, J., and Buchanan, D. (2013). Is chronic pain a disease? Pain Med. 14, 1284-1288. doi: 10.1111/pme.12025

Cottam, W. J., Iwabuchi, S. J., Drabek, M. M., Reckziegel, D., and Auer, D. P. (2018). Altered connectivity of the right anterior insula drives the pain connectome changes in chronic knee osteoarthritis. Pain 159, 929-938. doi: 10.1097/j.pain.0000000000001209

Davis, K. D., and Moayedi, M. (2013). Central mechanisms of pain revealed through functional and structural MRI. J. Neuroimmune Pharmacol. 8, 518-534. doi: 10.1007/s11481-012-9386-8

Davis, K. D., Taub, E., Duffner, F., Lozano, A. M., Tasker, R. R., Houle, S., et al. (2000). Activation of the anterior cingulate cortex by thalamic stimulation in patients with chronic pain: a positron emission tomography study. J. Neurosurg. 92, 64-69. doi: 10.3171/jns.2000.92.1.0064

Duerden, E. G., and Albanese, M. C. (2013). Localization of pain-related brain activation: a meta-analysis of neuroimaging data. Hum. Brain Mapp. 34, 109-149. doi: 10.1002/hbm.21416

Duff, E. P., Vennart, W., Wise, R. G., Howard, M. A., Harris, R. E., Lee, M., et al. (2015). Learning to identify CNS drug action and efficacy using multistudy fMRI data. Sci. Transl. Med. 7:274ra216. doi: 10.1126/scitranslmed.300 8438

Duncan, G. H., Kupers, R. C., Marchand, S., Villemure, J. G., Gybels, J. M., and Bushnell, M. C. (1998). Stimulation of human thalamus for pain relief: possible modulatory circuits revealed by positron emission tomography. $J$. Neurophysiol. 80, 3326-3330. doi: 10.1152/jn.1998.80.6.3326

Eccleston, C. (1994). Chronic pain and attention: a cognitive approach. Br. J. Clin. Psychol. 33, 535-547. doi: 10.1111/j.2044-8260.1994.tb01150.x

Eickhoff, S. B., Bzdok, D., Laird, A. R., Kurth, F., and Fox, P. T. (2012). Activation likelihood estimation meta-analysis revisited. Neuroimage 59, 2349-2361. doi: 10.1016/j.neuroimage.2011.09.017

Flodin, P., Martinsen, S., Mannerkorpi, K., Lofgren, M., Bileviciute-Ljungar, I., Kosek, E., et al. (2015). Normalization of aberrant resting state functional connectivity in fibromyalgia patients following a three month physical exercise therapy. Neuroimage Clin 9, 134-139. doi: 10.1016/j.nicl.2015. 08.004

Friebel, U., Eickhoff, S. B., and Lotze, M. (2011). Coordinate-based meta-analysis of experimentally induced and chronic persistent neuropathic pain. Neuroimage 58, 1070-1080. doi: 10.1016/j.neuroimage.2011.07.022

Fu, K. Y., Light, A. R., and Maixner, W. (2001). Long-lasting inflammation and long-term hyperalgesia after subcutaneous formalin injection into the rat hindpaw. J. Pain 2, 2-11. doi: 10.1054/jpai.2001.9804

Geha, P., Yang, Y., Estacion, M., Schulman, B. R., Tokuno, H., Apkarian, A. V., et al. (2016). Pharmacotherapy for pain in a family with inherited erythromelalgia guided by genomic analysis and functional profiling. JAMA Neurol. 73, 659-667. doi: 10.1001/jamaneurol.2016.0389

Geha, P. Y., Baliki, M. N., Chialvo, D. R., Harden, R. N., Paice, J. A., and Apkarian, A. V. (2007). Brain activity for spontaneous pain of postherpetic neuralgia and its modulation by lidocaine patch therapy. Pain 128, 88-100. doi: 10.1016/j.pain.2006.09.014

Grazzi, L., Chiapparini, L., Ferraro, S., Usai, S., Andrasik, F., Mandelli, M. L., et al. (2010). Chronic migraine with medication overuse pre-post withdrawal of symptomatic medication: clinical results and FMRI correlations. Headache 50, 998-1004. doi: 10.1111/j.1526-4610.2010.01695.x

Groh, A., Krieger, P., Mease, R. A., and Henderson, L. (2018). Acute and chronic pain processing in the thalamocortical system of humans and animal models. Neuroscience 387, 58-71. doi: 10.1016/j.neuroscience.2017.09.042 
Gustin, S. M., Schwarz, A., Birbaumer, N., Sines, N., Schmidt, A. C., Veit, R., et al. (2010). NMDA-receptor antagonist and morphine decrease CRPS-pain and cerebral pain representation. Pain 151, 69-76. doi: 10.1016/j.pain.2010.06.022

Gwilym, S. E., Filippini, N., Douaud, G., Carr, A. J., and Tracey, I. (2010). Thalamic atrophy associated with painful osteoarthritis of the hip is reversible after arthroplasty: a longitudinal voxel-based morphometric study. Arthritis Rheum. 62, 2930-2940. doi: 10.1002/art.27585

Haroutounian, S., Nikolajsen, L., Bendtsen, T. F., Finnerup, N. B., Kristensen, A. D., Hasselstrom, J. B., et al. (2014). Primary afferent input critical for maintaining spontaneous pain in peripheral neuropathy. Pain 155, 1272-1279. doi: 10.1016/j.pain.2014.03.022

Harris, R. E., Napadow, V., Huggins, J. P., Pauer, L., Kim, J., Hampson, J., et al. (2013). Pregabalin rectifies aberrant brain chemistry, connectivity, and functional response in chronic pain patients. Anesthesiology 119, 1453-1464. doi: 10.1097/ALN.0000000000000017

Harris, R. E., Zubieta, J. K., Scott, D. J., Napadow, V., Gracely, R. H., and Clauw, D. J. (2009). Traditional Chinese acupuncture and placebo (sham) acupuncture are differentiated by their effects on mu-opioid receptors (MORs). Neuroimage 47, 1077-1085. doi: 10.1016/j.neuroimage.2009.05.083

Harte, S. E., Ichesco, E., Hampson, J. P., Peltier, S. J., Schmidt-Wilcke, T., Clauw, D. J., et al. (2016). Pharmacologic attenuation of cross-modal sensory augmentation within the chronic pain insula. Pain 157, 1933-1945. doi: $10.1097 /$ j.pain.0000000000000593

Hashmi, J. A., Baria, A. T., Baliki, M. N., Huang, L., Schnitzer, T. J., and Apkarian, A. V. (2012). Brain networks predicting placebo analgesia in a clinical trial for chronic back pain. Pain 153, 2393-2402. doi: 10.1016/j.pain.2012.08.008

Hemington, K. S., Wu, Q., Kucyi, A., Inman, R. D., and Davis, K. D. (2016). Abnormal cross-network functional connectivity in chronic pain and its association with clinical symptoms. Brain Struct. Funct. 221, 4203-4219. doi: 10.1007/s00429-015-1161-1

Henry, D. E., Chiodo, A. E., and Yang, W. (2011). Central nervous system reorganization in a variety of chronic pain states: a review. $P M R 3,1116-1125$. doi: 10.1016/j.pmrj.2011.05.018

Higgins, J. P., Thomas, J., Chandler, J., Cumpston, M., Li, T., Page, M. J., et al. (2019). Cochrane Handbook for Systematic Reviews of Interventions. Chichester: John Wiley and Sons. doi: 10.1002/9781119536604

Hosobuchi, Y., Adams, J. E., and Rutkin, B. (1973). Chronic thalamic stimulation for the control of facial anesthesia dolorosa. Arch. Neurol. 29, 158-161. doi: 10.1001/archneur.1973.00490270040005

Hruschak, V., and Cochran, G. (2018). Psychosocial predictors in the transition from acute to chronic pain: a systematic review. Psychol. Health Med. 23, 1151-1167. doi: 10.1080/13548506.2018.1446097

Hylands-White, N., Duarte, R. V., and Raphael, J. H. (2017). An overview of treatment approaches for chronic pain management. Rheumatol. Int. 37, 29-42. doi: 10.1007/s00296-016-3481-8

Jensen, K. B., Kosek, E., Wicksell, R., Kemani, M., Olsson, G., Merle, J. V., et al. (2012). Cognitive behavioral therapy increases pain-evoked activation of the prefrontal cortex in patients with fibromyalgia. Pain 153, 1495-1503. doi: 10.1016/j.pain.2012.04.010

Jensen, K. B., Petzke, F., Carville, S., Choy, E., Fransson, P., Gracely, R. H., et al. (2014). Segregating the cerebral mechanisms of antidepressants and placebo in fibromyalgia. J. Pain 15, 1328-1337. doi: 10.1016/j.jpain.2014. 09.011

Jensen, K. B., Regenbogen, C., Ohse, M. C., Frasnelli, J., Freiherr, J., and Lundstrom, J. N. (2016). Brain activations during pain: a neuroimaging metaanalysis of patients with pain and healthy controls. Pain 157, 1279-1286. doi: 10.1097/j.pain.0000000000000517

Jensen, M. P., Day, M. A., and Miro, J. (2014). Neuromodulatory treatments for chronic pain: efficacy and mechanisms. Nat. Rev. Neurol. 10, 167-178. doi: 10.1038/nrneurol.2014.12

Kim, S. H., Lee, Y., Lee, S., and Mun, C. W. (2013). Evaluation of the effectiveness of pregabalin in alleviating pain associated with fibromyalgia: using functional magnetic resonance imaging study. PLoS ONE 8:e74099. doi: 10.1371/journal.pone.0074099

Kishima, H., Saitoh, Y., Oshino, S., Hosomi, K., Ali, M., Maruo, T., et al. (2010). Modulation of neuronal activity after spinal cord stimulation for neuropathic pain; H(2)15O PET study. Neuroimage 49, 2564-2569. doi: 10.1016/j.neuroimage.2009.10.054
Koeppe, C., Schneider, C., Thieme, K., Mense, S., Stratz, T., Muller, W., et al. (2004). The influence of the 5-HT3 receptor antagonist tropisetron on pain in fibromyalgia: a functional magnetic resonance imaging pilot study. Scand. J. Rheumatol. Suppl. 119, 24-27. doi: 10.1080/03009740410006989

Kupers, R. C., Gybels, J. M., and Gjedde, A. (2000). Positron emission tomography study of a chronic pain patient successfully treated with somatosensory thalamic stimulation. Pain 87, 295-302. doi: 10.1016/S0304-3959(00)00295-5

Lackner, J. M., Lou Coad, M., Mertz, H. R., Wack, D. S., Katz, L. A., Krasner, S. S., et al. (2006). Cognitive therapy for irritable bowel syndrome is associated with reduced limbic activity, GI symptoms, and anxiety. Behav. Res. Ther. 44, 621-638. doi: 10.1016/j.brat.2005.05.002

Lanz, S., Seifert, F., and Maihofner, C. (2011). Brain activity associated with pain, hyperalgesia and allodynia: an ALE meta-analysis. J. Neural Transm. (Vienna). 118, 1139-1154. doi: 10.1007/s00702-011-0606-9

Latremoliere, A., and Woolf, C. J. (2009). Central sensitization: a generator of pain hypersensitivity by central neural plasticity. J. Pain 10, 895-926. doi: 10.1016/j.jpain.2009.06.012

Lee, I. S., Necka, E. A., and Atlas, L. Y. (2020). Distinguishing pain from nociception, salience, and arousal: how autonomic nervous system activity can improve neuroimaging tests of specificity. Neuroimage 204:116254. doi: 10.1016/j.neuroimage.2019.116254

Legrain, V., Iannetti, G. D., Plaghki, L., and Mouraux, A. (2011). The pain matrix reloaded: a salience detection system for the body. Prog. Neurobiol. 93, 111-124. doi: 10.1016/j.pneurobio.2010.10.005

Li, J., Zhang, J. H., Yi, T., Tang, W. J., Wang, S. W., and Dong, J. C. (2014). Acupuncture treatment of chronic low back pain reverses an abnormal brain default mode network in correlation with clinical pain relief. Acupunct. Med. 32, 102-108. doi: 10.1136/acupmed-2013-010423

Li, K., Zhang, Y., Ning, Y., Zhang, H., Liu, H., Fu, C., et al. (2015). The effects of acupuncture treatment on the right frontoparietal network in migraine without aura patients. J. Headache Pain 16:518. doi: 10.1186/s10194-015-0518-4

Li, Z., Zeng, F., Yin, T., Lan, L., Makris, N., Jorgenson, K., et al. (2017). Acupuncture modulates the abnormal brainstem activity in migraine without aura patients. Neuroimage Clin. 15, 367-375. doi: 10.1016/j.nicl.2017.05.013

Lieberman, M. D., Jarcho, J. M., Berman, S., Naliboff, B. D., Suyenobu, B. Y., Mandelkern, M., et al. (2004). The neural correlates of placebo effects: a disruption account. Neuroimage 22, 447-455. doi: 10.1016/j.neuroimage.2004.01.037

Linnman, C., Catana, C., Svardsudd, K., Appel, L., Engler, H., Langstrom, B., et al. (2016). Decreased brain neurokinin-1 receptor availability in chronic tennis elbow. PLoS ONE 11:e0161563. doi: 10.1371/journal.pone.0161563

Lopez-Sola, M., Woo, C. W., Pujol, J., Deus, J., Harrison, B. J., Monfort, J., et al. (2017). Towards a neurophysiological signature for fibromyalgia. Pain 158, 34-47. doi: 10.1097/j.pain.0000000000000707

Maarrawi, J., Peyron, R., Mertens, P., Costes, N., Magnin, M., Sindou, M., et al. (2007). Motor cortex stimulation for pain control induces changes in the endogenous opioid system. Neurology 69, 827-834. doi: 10.1212/01.wnl.0000269783.86997.37

Magis, D., Bruno, M. A., Fumal, A., Gerardy, P. Y., Hustinx, R., Laureys, S., et al. (2011). Central modulation in cluster headache patients treated with occipital nerve stimulation: an FDG-PET study. BMC Neurol. 11:25. doi: 10.1186/1471-2377-11-25

Mansour, A. R., Baliki, M. N., Huang, L., Torbey, S., Herrmann, K. M., Schnitzer, T. J., et al. (2013). Brain white matter structural properties predict transition to chronic pain. Pain 154, 2160-2168. doi: 10.1016/j.pain.2013.06.044

Mayer, D. J., and Liebeskind, J. C. (1974). Pain reduction by focal electrical stimulation of the brain: an anatomical and behavioral analysis. Brain Res. 68, 73-93. doi: 10.1016/0006-8993(74)90534-4

Mayer, E. A., Berman, S., Derbyshire, S. W., Suyenobu, B., Chang, L., Fitzgerald, L., et al. (2002). The effect of the 5-HT3 receptor antagonist, alosetron, on brain responses to visceral stimulation in irritable bowel syndrome patients. Aliment. Pharmacol. Ther. 16, 1357-1366. doi: 10.1046/j.1365-2036.2002.01287.x

Mazars, G. J. (1975). Intermittent stimulation of nucleus ventralis posterolateralis for intractable pain. Surg. Neurol. 4, 93-95.

Melzack, R. (2001). Pain and the neuromatrix in the brain. J. Dent. Educ. 65, 1378-1382. doi: 10.1002/j.0022-0337.2001.65.12.tb03497.x

Micalos, P. S., Korgaonkar, M. S., Drinkwater, E. J., Cannon, J., and Marino, F. E. (2014). Cerebral responses to innocuous somatic pressure 
stimulation following aerobic exercise rehabilitation in chronic pain patients: a functional magnetic resonance imaging study. Int. J. Gen. Med. 7, 425-432. doi: 10.2147/IJGM.S55169

Moher, D., Liberati, A., Tetzlaff, J., Altman, D. G., and Group, P. (2009). Preferred reporting items for systematic reviews and meta-analyses: the PRISMA statement. Ann. Intern. Med. 151, 264-269, W264. doi: 10.7326/0003-4819-151-4-200908180-00135

Mouraux, A., and Iannetti, G. D. (2018). The search for pain biomarkers in the human brain. Brain 141, 3290-3307. doi: 10.1093/brain/awy281

Napadow, V., Kettner, N., Liu, J., Li, M., Kwong, K. K., Vangel, M., et al. (2007). Hypothalamus and amygdala response to acupuncture stimuli in Carpal Tunnel Syndrome. Pain 130, 254-266. doi: 10.1016/j.pain.2006. 12.003

Napadow, V., Kim, J., Clauw, D. J., and Harris, R. E. (2012). Decreased intrinsic brain connectivity is associated with reduced clinical pain in fibromyalgia. Arthritis Rheum. 64, 2398-2403. doi: 10.1002/art.34412

Parks, E. L., Geha, P. Y., Baliki, M. N., Katz, J., Schnitzer, T. J., and Apkarian, A. V. (2011). Brain activity for chronic knee osteoarthritis: dissociating evoked pain from spontaneous pain. Eur. J. Pain 15, 843.e1-843.e14. doi: 10.1016/j.ejpain.2010.12.007

Petzke, F., Jensen, K. B., Kosek, E., Choy, E., Carville, S., Fransson, P., et al. (2013). Using fMRI to evaluate the effects of milnacipran on central pain processing in patients with fibromyalgia. Scand. J. Pain 4, 65-74. doi: 10.1016/j.sjpain.2012.10.002

Pinto-Sanchez, M. I., Hall, G. B., Ghajar, K., Nardelli, A., Bolino, C., Lau, J. T., et al. (2017). Probiotic Bifidobacterium longum NCC3001 reduces depression scores and alters brain activity: a pilot study in patients with irritable bowel syndrome. Gastroenterology 153, 448.e8-459.e8. doi: 10.1053/j.gastro.2017.05.003

Pockett, S. (1995). Spinal cord synaptic plasticity and chronic pain. Anesth. Analg. 80, 173-179. doi: 10.1213/00000539-199501000-00026

Privitera, R., Birch, R., Sinisi, M., Mihaylov, I. R., Leech, R., and Anand, P. (2017). Capsaicin 8\% patch treatment for amputation stump and phantom limb pain: a clinical and functional MRI study. J. Pain Res. 10, 1623-1634. doi: 10.2147/JPR.S140925

Qiu, E., Tian, L., Wang, Y., Ma, L., and Yu, S. (2015). Abnormal coactivation of the hypothalamus and salience network in patients with cluster headache. Neurology 84, 1402-1408. doi: 10.1212/WNL.0000000000001442

Raffaeli, W., and Arnaudo, E. (2017). Pain as a disease: an overview. J. Pain Res. 10, 2003-2008. doi: 10.2147/JPR.S138864

Rhodes, D. L., and Liebeskind, J. C. (1978). Analgesia from rostral brain stem stimulation in the rat. Brain Res. 143, 521-532. doi: 10.1016/0006-8993(78)90362-1

Rogachov, A., Bhatia, A., Cheng, J. C., Bosma, R. L., Kim, J. A., Osborne, N. R., et al. (2019). Plasticity in the dynamic pain connectome associated with ketamine-induced neuropathic pain relief. Pain 160, 1670-1679. doi: $10.1097 /$ j.pain.0000000000001545

Sanders, D., Krause, K., O'muircheartaigh, J., Thacker, M. A., Huggins, J. P., Vennart, W., et al. (2015). Pharmacologic modulation of hand pain in osteoarthritis: a double-blind placebo-controlled functional magnetic resonance imaging study using naproxen. Arthritis Rheumatol. 67, 741-751. doi: 10.1002/art.38987

Sawaddiruk, P., Apaijai, N., Paiboonworachat, S., Kaewchur, T., Kasitanon, N., Jaiwongkam, T., et al. (2019). Coenzyme Q10 supplementation alleviates pain in pregabalin-treated fibromyalgia patients via reducing brain activity and mitochondrial dysfunction. Free Radic. Res. 53, 901-909. doi: 10.1080/10715762.2019.1645955

Seminowicz, D. A., Wideman, T. H., Naso, L., Hatami-Khoroushahi, Z., Fallatah, S., Ware, M. A., et al. (2011). Effective treatment of chronic low back pain in humans reverses abnormal brain anatomy and function. J. Neurosci. 31, 7540-7550. doi: 10.1523/JNEUROSCI.5280-10.2011

Shpaner, M., Kelly, C., Lieberman, G., Perelman, H., Davis, M., Keefe, F. J., et al. (2014). Unlearning chronic pain: a randomized controlled trial to investigate changes in intrinsic brain connectivity following cognitive behavioral therapy. Neuroimage Clin. 5, 365-376. doi: 10.1016/j.nicl.2014.07.008

Smallwood, R. F., Laird, A. R., Ramage, A. E., Parkinson, A. L., Lewis, J., Clauw, D. J., et al. (2013). Structural brain anomalies and chronic pain: a quantitative meta-analysis of gray matter volume. J. Pain 14, 663-675. doi: 10.1016/j.jpain.2013.03.001
Smallwood, R. F., Potter, J. S., and Robin, D. A. (2016). Neurophysiological mechanisms in acceptance and commitment therapy in opioid-addicted patients with chronic pain. Psychiatry Res. Neuroimaging 250, 12-14. doi: 10.1016/j.pscychresns.2016.03.001

Sullivan, M. D., Cahana, A., Derbyshire, S., and Loeser, J. D. (2013). What does it mean to call chronic pain a brain disease? J. Pain 14, 317-322. doi: 10.1016/j.jpain.2012.02.012

Talbot, J. D., Marrett, S., Evans, A. C., Meyer, E., Bushnell, M. C., and Duncan, G. H. (1991). Multiple representations of pain in human cerebral cortex. Science 251, 1355-1358. doi: 10.1126/science.2003220

Tanasescu, R., Cottam, W. J., Condon, L., Tench, C. R., and Auer, D. P. (2016). Functional reorganisation in chronic pain and neural correlates of pain sensitisation: a coordinate based meta-analysis of 266 cutaneous pain fMRI studies. Neurosci. Biobehav. Rev. 68, 120-133. doi: 10.1016/j.neubiorev.2016.04.001

Taylor, A. G., Anderson, J. G., Riedel, S. L., Lewis, J. E., and Bourguignon, C. (2013). A randomized, controlled, double-blind pilot study of the effects of cranial electrical stimulation on activity in brain pain processing regions in individuals with fibromyalgia. Explore (NY) 9, 32-40. doi: 10.1016/j.explore.2012.10.006

Taylor, A. M., Becker, S., Schweinhardt, P., and Cahill, C. (2016). Mesolimbic dopamine signaling in acute and chronic pain: implications for motivation, analgesia, and addiction. Pain 157, 1194-1198. doi: $10.1097 /$ j.pain.0000000000000494

Tetreault, P., Baliki, M. N., Baria, A. T., Bauer, W. R., Schnitzer, T. J., and Apkarian, A. V. (2018). Inferring distinct mechanisms in the absence of subjective differences: placebo and centrally acting analgesic underlie unique brain adaptations. Hum. Brain Mapp. 39, 2210-2223. doi: 10.1002/hbm.23999

Thomas Cheng, H. (2010). Spinal cord mechanisms of chronic pain and clinical implications. Curr. Pain Headache Rep. 14, 213-220. doi: 10.1007/s11916-010-0111-0

Tillisch, K., Labus, J., Nam, B., Bueller, J., Smith, S., Suyenobu, B., et al. (2012). Neurokinin-1-receptor antagonism decreases anxiety and emotional arousal circuit response to noxious visceral distension in women with irritable bowel syndrome: a pilot study. Aliment. Pharmacol. Ther. 35, 360-367. doi: 10.1111/j.1365-2036.2011.04958.x

Timmers, I., de Jong, J. R., Goossens, M., Verbunt, J. A., Smeets, R. J., Kaas, A. L., et al. (2019). Exposure in vivo induced changes in neural circuitry for pain-related fear: a longitudinal fMRI study in chronic low back pain. Front. Neurosci. 13:970. doi: 10.3389/fnins.2019.00970

Tracey, I., and Bushnell, M. C. (2009). How neuroimaging studies have challenged us to rethink: is chronic pain a disease? J. Pain 10, 1113-1120. doi: 10.1016/j.jpain.2009.09.001

Tracey, I., and Mantyh, P. W. (2007). The cerebral signature for pain perception and its modulation. Neuron 55, 377-391. doi: 10.1016/j.neuron.2007.07.012

Treede, R.-D., Rief, W., Barke, A., Aziz, Q., Bennett, M. I., Benoliel, R., et al. (2015). A classification of chronic pain for ICD-11. Pain 156, 1003-1007. doi: 10.1097/j.pain.0000000000000160

Treede, R. D., Rief, W., Barke, A., Aziz, Q., Bennett, M. I., Benoliel, R., et al. (2019). Chronic pain as a symptom or a disease: the IASP classification of chronic pain for the International Classification of Diseases (ICD-11). Pain 160, 19-27. doi: $10.1097 /$ j.pain.0000000000001384

Vachon-Presseau, E., Centeno, M. V., Ren, W., Berger, S. E., Tetreault, P., Ghantous, M., et al. (2016a). The emotional brain as a predictor and amplifier of chronic pain. J. Dent. Res. 95, 605-612. doi: 10.1177/002203451663 8027

Vachon-Presseau, E., Tetreault, P., Petre, B., Huang, L., Berger, S. E., Torbey, S., et al. (2016b). Corticolimbic anatomical characteristics predetermine risk for chronic pain. Brain 139, 1958-1970. doi: 10.1093/brain/ aww100

Wager, T. D., Atlas, L. Y., Lindquist, M. A., Roy, M., Woo, C. W., and Kross, E. (2013). An fMRI-based neurologic signature of physical pain. N. Engl. J. Med. 368, 1388-1397. doi: 10.1056/NEJMoa1204471

Walitt, B., Roebuck-Spencer, T., Esposito, G., Atkins, F., Bleiberg, J., Foster, G., et al. (2007). The effects of multidisciplinary therapy on positron emission tomography of the brain in fibromyalgia: a pilot study. Rheumatol. Int. 27, 1019-1024. doi: 10.1007/s00296-007-0405-7

Wallace, D. J., Linker-Israeli, M., Hallegua, D., Silverman, S., Silver, D., and Weisman, M. H. (2001). Cytokines play an aetiopathogenetic role in 
fibromyalgia: a hypothesis and pilot study. Rheumatology (Oxford) 40, 743-749. doi: 10.1093/rheumatology/40.7.743

Woolf, C. J. (2011). Central sensitization: implications for the diagnosis and treatment of pain. Pain 152, S2-S15. doi: 10.1016/j.pain.2010.09.030

Yoon, E. J., Kim, Y. K., Kim, H. R., Kim, S. E., Lee, Y., and Shin, H. I. (2014). Transcranial direct current stimulation to lessen neuropathic pain after spinal cord injury: a mechanistic PET study. Neurorehabil. Neural Repair 28, 250-259. doi: $10.1177 / 1545968313507632$

Yoshino, A., Okamoto, Y., Okada, G., Takamura, M., Ichikawa, N., Shibasaki, C., et al. (2018). Changes in resting-state brain networks after cognitivebehavioral therapy for chronic pain. Psychol. Med. 48, 1148-1156. doi: $10.1017 /$ S0033291717002598

Zang, Y. F., Zuo, X. N., Milham, M., and Hallett, M. (2015). Toward a meta-analytic synthesis of the resting-state fMRI literature for clinical populations. Biomed. Res. Int. 2015, 435265. doi: 10.1155/2015/435265

Zhang, Y., Li, K. S., Liu, H. W., Fu, C. H., Chen, S., Tan, Z. J., et al. (2016). Acupuncture treatment modulates the resting-state functional connectivity of brain regions in migraine patients without aura. Chin. J. Integr. Med. 22, 293-301. doi: 10.1007/s11655-015-2042-4

Zhao, J. M., Lu, J. H., Yin, X. J., Chen, X. K., Chen, Y. H., Tang, W. J., et al. (2015). Comparison of electroacupuncture and moxibustion on brain-gut function in patients with diarrhea-predominant irritable bowel syndrome: a randomized controlled trial. Chin. J. Integr. Med. 21, 855-865. doi: 10.1007/s11655-015-2049-x

Zhao, J. M., Lu, J. H., Yin, X. J., Wu, L. Y., Bao, C. H., Chen, X. K., et al. (2018). Comparison of electroacupuncture and mild-warm moxibustion on brain-gut function in patients with constipation-predominant irritable bowel syndrome: a randomized controlled trial. Chin. J. Integr. Med. 24, 328-335. doi: 10.1007/s11655-018-2838-0

Zou, Y., Tang, W., Li, X., Xu, M., and Li, J. (2019). Acupuncture reversible effects on altered default mode network of chronic migraine accompanied with clinical symptom relief. Neural Plast. 2019:5047463. doi: 10.1155/2019/5047463

Conflict of Interest: The authors declare that the research was conducted in the absence of any commercial or financial relationships that could be construed as a potential conflict of interest.

Copyright () 2021 Kim, Chae, Park and Lee. This is an open-access article distributed under the terms of the Creative Commons Attribution License (CC BY). The use, distribution or reproduction in other forums is permitted, provided the original author(s) and the copyright owner(s) are credited and that the original publication in this journal is cited, in accordance with accepted academic practice. No use, distribution or reproduction is permitted which does not comply with these terms. 